CHAPTER 20

\title{
MODES OF SEDIMENT BEHAVIOR AND SELECTION OF HARBOR DESIGN AND MAINTENANCE TECHNIQUES FOR MINIMUM SHOALING IN ESTUARIES
}

\author{
R. B. Krone and H. A. Einstein \\ Sanitary Engineering Research Laboratory \\ and \\ Hydraulic Engineering Laboratory \\ University of California, Berkeley
}

\section{INTRODUCTION}

Recent field and laboratory studies on San Francisco Bay sediment have revealed modes of sediment transport and shoaling processes there. These studies have been partially described in reports (Krone et al., 1959, 1960) and articles (Einstein and Krone, 196la, b) and sufficient informatior has now been accumulated to encourage qualitative recommendations for selecting harbor designs and maintenance programs causing minimum shoaling in this bay.

San Francisco Bay is a transitional region between the nearly steadj uniform fresh-water flows in contiguous rivers and the marine environment. In this region unsteady quasiperiodic flows and water depths prevail, and salinities range from very low values in the rivers to that of sea water. Water density variations due to salinity differences complicate hydraulic conditions resulting from the transition from river to tide-induced flows, particularly in channels, to the extent that flows in opposite directions are found near the channel bottom and near the water surface. Large areas exist in the Bay with MLIW depths less than six feet. In these areas wind and tide-induced currents having low flow velocities, and wave action are the important hydraulic conditions.

The sediments transported into the Bay generally range from fine sand downward in size, and compose the "wash loads" of entering streams that have found conditions in the Bay favoring deposition. Sediments involved ir shoaling problems are generally composed of more than half clay minerals. These minerals are a heterogeneous mixture but are predominately montmorillonite and illite. Organic matter content of deposits within the Bay are or the order of .02 by dry weight.

Similar estuarial conditions and clayey sediments to those in San Francisco Bay are believed to occur widely in other areas, with variations in detail of configuration, flows, salinities, wave action, and sediment composition and loads. Such details are more or less subject to modification, however, and are the principal interest of those concerned with harbox design. This paper first presents descriptions of the factors and physical processes important to sediment transport and shoaling in an estuarial environment as bases of later general recommendations for harbor design and mair tenance. These descriptions are based on the San Francisco Bay studies, with supplementary information from other estuarial regions when known.

\section{SEDTMENTS}

The large clay mineral portion of San Francisco Bay sediment results from the enhanced deposition of such particles when they enter an estuarial 
COASTAL ENGINEERING
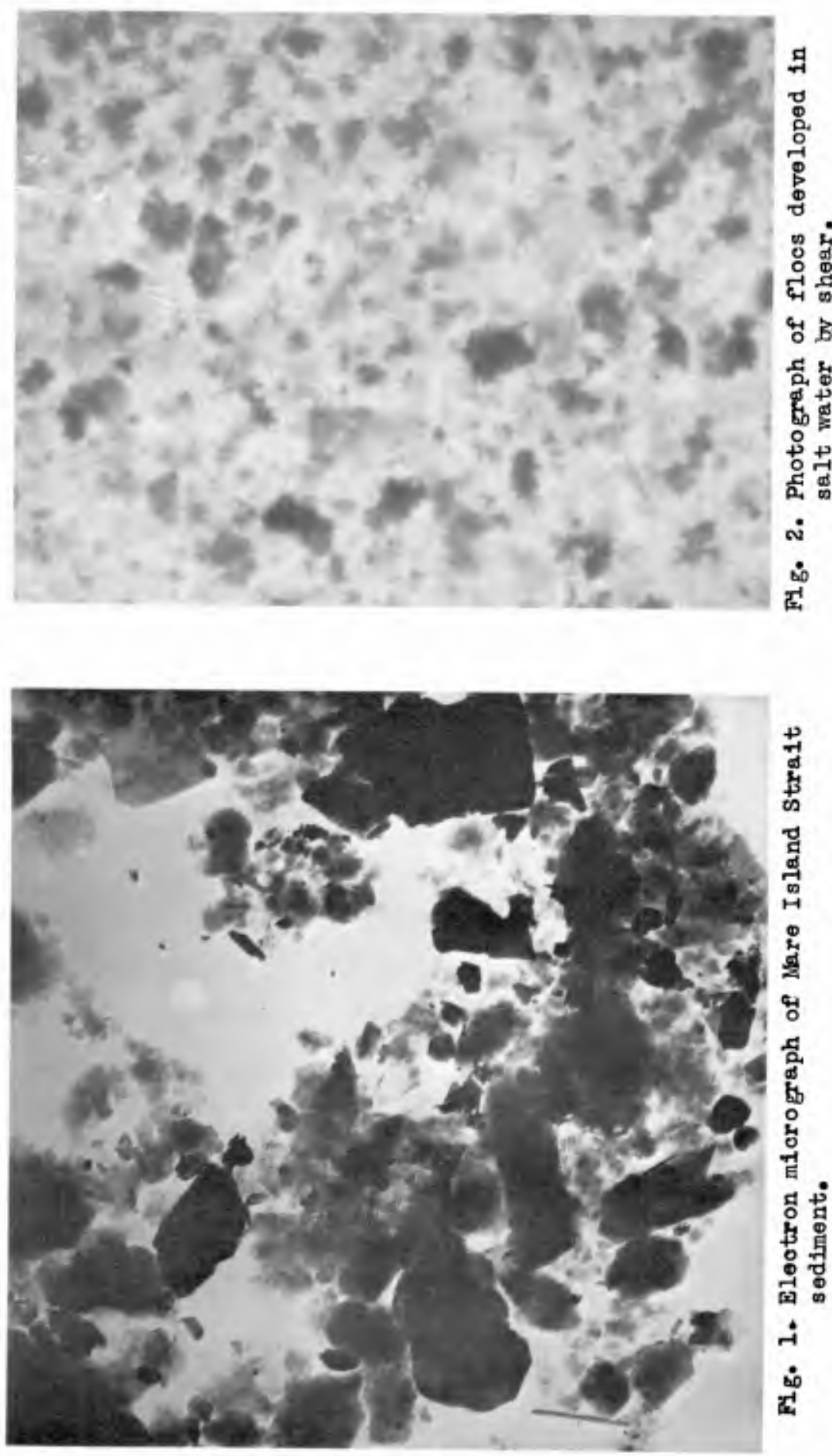


\section{MODES OF SEDIMENT BEHAVIOR AND SELECTION \\ OF HARBOR DESIGN AND MAINTENANCE \\ TECHNIQUES FOR MINIMUM SHOALING \\ IN ESTUARIES}

environment. An electron micrograph of sediment taken from a part of the San Francisco Bay system is shown in Figure 1. The particle sizes in Figure 1 can be estimated by comparison with the approximately one-micron long halloysite tube in the lower left-hand corner. The large flakes in the figure are illite particles, and the fine indistinct masses are believed to be montmorillonite. Figure 1 shows the variety of shapes and sizes of such minerals.

The mineral composition depends on the soils in the areas drained by entering streams. It is unlikely that an estuarial sediment contains only one mineral kind, although one can predominate. Mineral compositions determined by X-ray analyses of sediments supplied by the Corps of Engineers, U. S. Army, from estuaries in the United States are summarized in Table 1. The compositions given in Table 1 show similar minerals with different relative abundances for samples taken from widely separated estuaries. The large fractions of particles less than $2 \mu$ give all of these samples a clayey character.

TABLE 1. Mineral Compositions of Estuarial Sediments

\begin{tabular}{|c|c|c|c|}
\hline & Location & $\begin{array}{l}\text { Fraction } \\
\quad<2\end{array}$ & $\begin{array}{l}\text { Minerals Present, } \\
\text { in order of abundance }\end{array}$ \\
\hline 1 . & Philadelphia & 0.54 & $\begin{array}{c}\text { montmorillonite, vermiculite, } \\
\text { kaolinite, } 11 \text { lite, quartz }\end{array}$ \\
\hline 2 . & Brunswick Harbor & 0.76 & $\begin{array}{l}\text { kaolinite, illite, montmoril- } \\
\text { lonite, vermiculite, quartz }\end{array}$ \\
\hline 3. & Gulfport Shlp Channel & 0.78 & $\begin{array}{l}\text { montmorillonite, kaolinite, } \\
\text { quartz }\end{array}$ \\
\hline 4. & Potomac River & 0.30 & $\begin{array}{l}\text { kaolinite, montmorillonite, } \\
\text { illite, quartz }\end{array}$ \\
\hline 5. & Delaware River & 0.47 & $\begin{array}{l}\text { illite, montmorillonite, } \\
\text { kaolinite, quartz }\end{array}$ \\
\hline 6. & $\begin{array}{l}\text { Mare Island Strait } \\
\text { (San Francisco Bay) }\end{array}$ & $0.60,0.47$ & $\begin{array}{l}\text { montmorillonite, illıte, } \\
\text { kaolinite, quartz }\end{array}$ \\
\hline
\end{tabular}

\section{FLOCCULATION}

Fine particles usually remain dispersed in river waters because coulombic repulsive forces predominate between colliding particles. The distribution of the energy of repulsion from a mineral particle surface depends on the valence and concentration gradient of ions in river waters attracted by the charges of the mineral surfaces. The charge density on a mineral is fixed by the mineral composition, so that as the concentration of 


\section{COASTAL ENGINEERING}

salt ions in the surrounding water increases, the gradient of ion concentr tion from the particle diminishes with a consequent lessening of repulsior

Short range attractive forces also exist between particles. These attractive forces are believed to be due to electro-magnetic interactions between atoms resulting from oscillations of the atomic nuclei within thei associated electron clouds. These forces are strong, short range, and add tive. Whether the repulsive or attractive forces predominate between coll ing particles depends on the salt and its concentration, for a given miner For San Francisco Bay sediment the attractive forces are completely effect at sea-salt concentrations of $1 \mathrm{~g} / \mathrm{l}$ and higher (Einstein and Krone, 196la) Since ocean water has a salt concentration of about $35 \mathrm{~g} / 1$, the salinity $c$ most of the mixing zone is sufficient to allow colliding particles to stic together.

Flocculation, or aggregation, of particles in an estuary requires both that particles be brought together and that colliding particles stick Three mechanisms of bringing particles together have been described (Krons et al., 1962): thermal agitation of the suspension, the internal shearins that comprises the flow process, and differential settling velocities.

Thermal agitation, or Brownian movement, results from thermal jostling of suspended particle by the erratic movements of neighboring water molecules The frequency of collisions on a particle or floc depends on the number of particles per cubic centimeter and the absolute temperature. Collisions $k$ this mechanism are important among the large number of particles per cubic centimeter that sometimes occur near the bed.

The frequency of collisions on a particle due to internal shearing in the water depends on the number of particles per cubic centimeter, on 1 collision radius of the particles cubed, and on the shearing rate. The cr lision radius is approximately the sum of the radil of the two colliding particles. Collisions are enhanced by a wide range of particle sizes (in cluding flocculent particles) which provide both large collision radil an large numbers per cubic centimeter. Internal shearing at rates up to $6 \mathrm{~cm} / \mathrm{sec}$ per cm cause growth of flocs of suspended San Francisco Bay seä. ment. At higher rates flocs are broken apart.

An enlarged photograph of sediment flocs developed in the laborat, by shearing the suspension between concentric cylinders is shown in Figur, The aggregation of smaller flocs into large ones can easily be seen in $F i$, ure 2. The darker areas in Figure 2 are flocs.

Collisions by differential settling velocities depend on the numb of particles per cubic centimeter, the difference in radil of the collidi particle pair and the collision radius cubed. Collisions due to both internal. shear and differential settling are enhanced by a range of floc si the large flocs tend to gather up the smaller ones, and to grow even larg Differential settling can continue growth of flocs initiated by shearing, and the two mechantsms enhance one another under conditions of gentle int nal shearing. These phenomena are utilized in water treatment to remove suspended particles.

of the various factors that promote flocculation, two are subject modification by the designer. They are the suspended sediment concentrat and the rates of internal shearing in a waterway. 


\section{MODES OF SEDIMENT BEHAVIOR AND SELECTION \\ OF HARBOR DESIGN AND MAINTENANCE \\ TECHNIQUES FOR MINIMUM SHOALING \\ IN ESTUARIES}

\section{SETPLING VELOCITTES}

A slgnificant consequence of flocculation is the alteration of settling velocities of suspended particles resulting from the increase in size of aggregates. The density of flocs depends on the salinity of the water, on the shapes and size distribution of the minerals, and on the composition of the individual sediment particles. The density of San Franciscc Bay sediment flocs was found to be between 1.03 to $1.07 \mathrm{~g} / \mathrm{cm}^{3}$ for a water density of $1.013 \mathrm{~g} / \mathrm{cm}^{3}$. The difference in density between the water and the floc is less for the floc ( 0.02 to 0.05$)$ than for an individual particle in fresh water (1.6), but the settling velocity is proportional to the radius squared, and the lower density is rapidly compensated by the increase in size. The settling velocity of a floc is greater than that of a $2-\mu$ particle for floc sizes above 18 to $12 \mu$ for the densities given. Large flocs have much higher settling velocities than do individual particles. When suspended sediment encounters conditions favoring rapid flocculation and the formation of large flocs, the increased settling velocities facilitate deposition.

A condition of "fluid mud" has been reported in estuaries. It has been observed in the laboratory that at suspended sediment concentrations above about $10 \mathrm{~g} / 1$ the settling flocs hinder the upflow of displaced water, and during the period of "hindered settling" the mud has a well-defined surface, just as would a more dense fluid under water. This phase lasted from 100 to 200 minutes for the sediments tested, and was followed by a slow "consolidation" phase.

\section{VISCOUS PROPERTIES}

Viscometer measurements on sediments from San Francisco Bay, Philadelphia, and the Gulfport Channel show that these sediments have the properties of a Bingham fluid. Both a capillary viscometer and a rotating cylinder viscometer show linear shear as shearing rate relations 'with an extrapolated initial shear strength at zero shearing rate. The initial shear strength increases with increasing concentration from a minimum concentration that provides a connected structure.

The initial shear strength also increases with salinity up to a maximum at the salinity of $1 \mathrm{~g} / \mathrm{I}$ for San Francisco Bay sediments, showing that maximum cohesion prevails at that and higher salinities.

The properties of the other sediments listed have not yet been studied with a viscometer. In view of their mineral compositions, however, they are expected to have similar rheological properties, but different strengths and differential viscosities.

\section{SEDTMENTT BED-FLOW INTERACIIONS}

Deposition rates of flocculent particles in suspension from flowing water depends on the amount of material in suspension, the floc settling velocities, and the bed shear. The settling velocities depend on the concentration of suspended material and internal shearing as described above Flume studies (Einstein and Krone, 1961b) have shown that flocculent particles of San Francisco Bay sediments striking the bed can stick at bed shears 


\section{COASTAL ENGINEERING}

less than 0.6 to 0.8 dynes $/ \mathrm{cm}^{2}$. Such shears occur in a 30 -ft deep channel at average uniform flow velocities of $0.93 \mathrm{ft} / \mathrm{sec}$. At lower shears the probability of a floc sticking to the bed increases proportionately.

Suspension of deposited flocculent sediment at bed shears greater than $0.8 \mathrm{dynes} / \mathrm{cm}^{2}$ appears to occur by two processes. Mass failure of the sediment deposit occurs when the bed shear exceeds the sediment shear strength-which can easily occur for freshly deposited sedinent or suspensions in the "fluid mud" concentration range on an increasing tidal current. When the shear strength of the bed is greater than the shear applied by the flow, a relatively slow erosion of the bed occurs. The erosion rate is weakly dependent on the suspended sediment concentration.

\section{TRANSPORT AND SHOALING PROCESSES}

A description of modes of transport and of shoaling processes can be derived from the foregoing descriptions of cohesive sediment behavior in suspension and of flow-bed interactions. These are summarized briefly:

1. Sediment can be transported long distances in suspension by tidal flows when the floc sizes are small or when the bed shears exceed the maximum at which deposition occurs. Floc sizes would remain small under conditions of high internal shearing rates or low suspended sediment concentrations. At high shearing rates and when the concentration of suspended sediment is high, the growth of rlocs combined with destruction of large flocs by internal shearing is believed to narrow the distribution of floc sizes. Limited field date support this.

2. When mud-laden water encounters flow conditions providing gentle internal shearing, such as those near sudden channel enlargements, docks and pilings in regions of low flow velocities, and near the interface of a saline wedge, very rapid growth of flocs occurs. The collision frequency on a flocculent particle under conditions of internal shearing depends on the collision radius cubed, making flocs grow at an increasing rate.

3. In areas and at times when the bed shear is sufficlently low, deposj tion of flccs can be rapid. Low bed shears and conditions of gentle internal shearing often occur together in docking areas constructed in channel enlargements.

4. Movement of "fluid mud" or high concentrations of flocculent sediment can occur as gravity flows wherever the bed slopes are sufficient to start and maintain such flows. Gravity flows can be an important mode of transport from zones of rapid deposition at the edge of a channel into the center part of the channel. Movement of a layer of fluid mud by shear of the water above alone is contradictory to the rheological characteristics of sediments studied and has not been found in radioactive tracer studies made to observe such movement In San Francisco Bay (Krone et al., 1959). 


\section{MODES OF SEDIMENT BEHAVIOR AND SELECTION \\ OF HARBOR DESIGN AND MAINTENANCE \\ TECHNIQUES FOR MINIMUM SHOALING \\ IN ESTUARIES}

\section{PRINCIPLES OF DESIGN AND MAINTENANCE ПTECHNIQUES}

Preparations for design of harbors or harbor modifications should include determination of sediment character, salinity distributions, and a description of the hydraulic regime. Procedures for making such determinations are outside the scope of this paper. Such information is necessary, however, for determining whether cohesive sediments and the regime described here is applicable, and for applying the principles suggested below. These principles are:

1. Minimize the suspended sediment concentration of water entering a probable shoaling area. Even occasional high concentrations can cause serious shoaling and should not be overlooked. Methods of minimizing the concentrations of suspended sediments include:

a. Prevent suspension of sediments in source areas. Shallow areas were found to provide sediment to suspension in San Francisco Bay during daily perlods of wave action. Such areas can sometimes economically be filled in.

b. Prevent tidal movements of water from source areas to the shoaling area. Dikes are feasible for containing dredge spoil and for increasing currents in channels through shallow areas. Such dikes can often be designed to include all shallow source areas.

c. Avoid contaminating an area of shoaling by dredge spoil from adjacent maintenance operations. Such difficulty is probable in a long, gradually widening estuary wherein dredging is in pro gress in some part of the estuary most of the time, and when dredge spoil is released into the waterway. Disposal in areas contained by dikes has been found to reduce shoaling by more than one-half from that which occurred during a period of spoiling to the waterway in the Delaware River (Simmons, 1962).

2. Minimize flow conditions combining enhanced internal shearing and low bed shears.

a. Channel enlargement for docking facilities reduces bed shears. Shoaling can be minimized by avoiding or minimizing flow conditions that provide gentle internal shearing such as those near pilings, sudden enlargements, and in salinity gradients. Gradual channel transitions, particularly those of the bed, and smooth channel boundaries are suggested. Parallel docking, if feasible, with covered dock faces should provide minimum disturbance to flows.

b. Both gentle internal shearing and low bed shears are provided by salinity intrusions, and shoaling is inevitable when clayey sediments are present. By combining flows or channel narrowing, the toe of a salinity intrusion can be moved and the shoaling area can be moved to a location where maintenance is more easily accomplished (Simmons, 1962).

3. Minimize the amount of sediment-laden water entering off-channel harbors. Since flow conditions that prevent deposition in such 


\section{COASTAL ENGINEERING}

areas cannot be provided, limitation of the amount of sediment-lader water entering a side channel or basin appears to be the best solution. Single narrow openings, providing essentially fill and draw water movement with a minimum of circulation, and entrance channels walled to water having low suspended sediment concentrations, are suggested.

4. Maintenance of bed shears greater than the maximum that allows deposition during most of a tidal cycle can be facilitated by dikes, which can be economical when used for multiple purposes as describec in $1 b$.

These principles support many present practices developed over many years of experience in estuaries. While they are based on laboratory and field studies in one transition region and are supported by experience in a limited number of other regions, they are based on widely applicable phenomena, and should serve as aids to selection of measurements in the field, evaluation of designs, interpretation of model data, and planning of maintenance operations.

\section{REF'ERENCES}

Krone, R. B., Einstein, H. A., Kaufman, W. J., and Orlob, G. T. (1959). Silt transport studies utilizing radioisotopes: 2nd Annual Progress Report, Hydraulic Engineering Laboratory and Sanitary Engineering Research Laboratory, University of California, Berkeley.

(1960). Silt transport studies utilizing radioisotopes: 3rd Annual Report, Hydraulic Engineering Laboratory and Sanitary Engineerink Research Laboratory, University of California, Berkeley.

Krone, R. B. (1962). Flume studies of the transport of sediment in estuarial shoaling processes: Final Report, Hydraulic Engineering Laborator: and Sanitary Engineering Research Laboratory, University of California, Berkeley.

Einstein, H. A. and Krone, R. B. (1961a). Estuarial sediment transport pat. terns: Proc. ASCE, vol. 87(HY2), Pt. 1, pp. 51-59.

(1961b). Experiments to determine the modes of cohesive sediment transport in salt water: J. Geophys. Res., vol. 67, pp. 1451-1461.

Simmons, H. B. (1962). Private conmunication. 